\title{
Operational Experiences of Industrial Scale AD: Lessons for the Future
}

\author{
Tanja Radu, Vincent Smedley, Andrew Wheatley \\ School of Civil and Building Engineering \\ Loughborough University \\ Loughborough, UK \\ T.Radu@lboro.ac.uk
}

\author{
Richard Blanchard \\ School of Electronic, Electrical and Systems Engineering \\ Loughborough University \\ Loughborough, UK
}

\author{
Helen Theaker \\ Unilever UK Ltd, \\ Burton upon Trent, UK
}

\begin{abstract}
In this paper we discuss operational experiences of two large industrial anaerobic digestion facilities processing brewery waste and maize. The raw effluent from the brewery waste has COD ranging from $5500 \mathrm{mg} / \mathrm{l}$ to $41400 \mathrm{mg} / \mathrm{l}$, with variable flow rate and suspended solids up to $4800 \mathrm{mg} / \mathrm{l}$. The AD treatment uses $900 \mathrm{~m}^{3}$ EGSB reactor. The two-year monitoring of data includes Ripley's Ratio, Volatile Fatty Acids, and pH. These parameters indicate lower performance and certain instability before the planned maintenance works, followed by the much improved performance afterwards. The average biogas production is $3540 \mathrm{Nm}^{3} /$ day but the variance of the biogas flow remains an issue.
\end{abstract}

The combined Heat and Power (CHP) production from energy crops uses ensilaged, purposely grown maize with $28-34 \%$ dry matter and chop length of $6-9 \mathrm{~mm}$. The available three-year data for this AD facilities indicate great process stability. It uses 150 t/day of maize, and result in energy production of $21 \mathrm{GW} /$ year which is 7000 homes equivalent. This energy is evenly split between the sewage treatment works and injection to the public electricity grid. Depending on the dry solids content, the digestate is either stored and spread on the land, or sold to farmers.

Index Terms-anaerobic digestion, brewery waste, energy crops, maize, biogas, EGSB

\section{INTRODUCTION}

Anaerobic digestion (AD) has, historically, mainly been used for pasteurizing sewage sludge. The anaerobic reduction of the organic material in waste contributes to the lower carbon emissions and decrease in landfill gas emissions. The increasing standards drive on environmental regulations imposed by governments in relation to the solid waste disposal or wastewater to sewer system has encouraged application of $\mathrm{AD}$ treatment in both developed and developing countries. In addition to waste reduction, $\mathrm{AD}$ provides an added benefit of efficient energy recovery. This has been further encouraged by the various government incentives, which have become especially attractive for the industrial scale AD. For example, Great Britain currently supports $\mathrm{AD}$ by the following incentives: Feed-in Tariffs (FITs), Renewables Obligation (RO) and accreditation for Renewables Obligation Certificates (ROCs), Renewable Heat Incentive (RHI), Levy Exemption Certificates and Renewable Transport Fuel Obligation (ref).

Treatment of food industries' and brewery waste in particular are some of the most common applications of AD. This is because of the usually high organic content and biodegradability of these wastes, with typically very high COD content originating from dissolved carbohydrates and alcohol. For example, the COD values of the brewery waste reported in literature range from $1200 \mathrm{mg} / \mathrm{l}$ (Leal et al 1998) to $125000 \mathrm{mg} / \mathrm{l}$. This high variability is due to the batch production and mixed process streams. Brewery industries effluent can be categorized as a medium-to-high strength organic wastewater, with very high energy requirements for the aeration (Parawira 2005). Furthermore, aerobic processes results in the generation of great quantities of waste sludge which needs further disposal hence increasing the total cost of the treatment. When compared with aerobic treatment, anaerobic treatment has lower running costs (Parawira 2005) with an added attraction of biogas production and the support of the renewable energy initiatives. Furthermore, the reported COD removal efficiency for AD treatment easily matches that of aerobic process, as it often reaches 90\% (Baloch 2007, Zheng 2012).

The Expanded Granular Sludge Bed (EGSB) process is the new generation of treatment systems which are becoming increasingly popular. In these types of reactors, very good settling of the bacterial granules prevents washout of the sludge and allows for very high upflow liquid velocity. Based on the design loading rates (OLR) of various AD processes, Franklin (Franklin 2001) reports that an average EGSB system operates loadings of $20 \mathrm{~kg} \mathrm{COD} / \mathrm{m}^{3} /$ day. He further argues that the increased loading rate capacity lowers the cost of the reactors and the overall cost of the process. There are numerous examples in literature where brewery waste has been successfully treated by the AD processes (Ahn 2001, Baloch 2007, Connaughton 2006). 
Anaerobic digestion of agricultural waste and purposegrown energy crops for biogas production has also become popular driven by the incentives. Maize, wheat and rice are the three most commonly grown crops in the world, with maize being the most common in terms of the total grain yield (Chandra 2012). Plant based feedstock (biomass) somewhat differs from the brewery waste because it also mostly consists of cellulose, hemicellulose and lignin, all of which are the building blocks of the plant cell walls (Chandra 2012). Published literature suggests various chemical mechanical and biological pre-treatment options to decrease crystallinity of cellulose and hemicellulose making the biomass more degradable. It was also suggested that ensilling of the biomass improves biogas yield when compared to the fresh material (Heiermann 2009). This implies that ensilling could also be considered a pre-treatment option for increasing biomass degradability.

In this paper, we are discussing control experiences of two industrial scale $\mathrm{AD}$, one using brewery waste and the other maize as feedstock. We analyze some of the stability parameters with performance including gas production.

\section{MATERIALS AND METHODS}

This section describes two industrial facilities treating brewery waste and purpose-grown maize using AD.

\section{A. Brewery waste}

Marmite Unilever AD facilities were first commissioned in 2008 and here we discuss the data collected over the 2 years, 2011 and 2012.

The AD reactor is a $900 \mathrm{~m}^{3}$ Biothane $^{\mathrm{R}}$ designed EGSB reactor. It is preceded by a $400 \mathrm{~m}^{3}$ buffering tank, which receives inflow stream and averages it in terms of flow and concentration. This is needed in order to prevent surges and toxicity shocks to the main reactor. Like many food effluents there is high variability in strength and composition of the effluent. The effluent of the main reactor circulates through a $28 \mathrm{~m}^{3}, 200 \mathrm{~m}^{3} / \mathrm{h}$ conditioning tank where the $\mathrm{pH} 7$ and temperature may be adjusted to $35^{\circ} \mathrm{C}$, when needed. The main function of the EGSB is to reduce COD and total suspended solids (TSS) of the effluent. The sludge bed contains granules with the mixed active colonies of both acidogenic and methanogenic bacteria. The reactor design includes a three phase separator (bio gas, liquid and solids) at the outlet to help with granule retention. The throughput of the tank is $10 \mathrm{~m}^{3} / \mathrm{h}$. Gas generated in the EGSB is sent either to boilers or a flare.

In this particular case study, the anaerobic reactor is followed by the aerobic Membrane Bioreactor (MBR) designed by Aquabio ${ }^{\mathrm{R}}$. Effluent from this reactor is further purified using reverse osmosis to allow recycling.

The inflow stream has variable composition. The $\mathrm{COD}_{\text {in }}$ was in range of $5540-41400 \mathrm{mg} / \mathrm{l}$ and total suspended solids (TSS) were in range $260-4860 \mathrm{mg} / \mathrm{l}$.

The waste water treatment plant runs mainly by automatic controls for $\mathrm{pH}$ and temperature. There is an occasional need for some manual intervention in special circumstances, e.g. high buffer tank volume or high Ripley's ratio. Tests of the following parameters are performed on daily basis: COD, suspended solids, Ripley's ratio, VFA and biogas production. Concentrations of $\mathrm{NH}_{3}$ and $\mathrm{PO}_{4}{ }^{3-}$ are checked several times per week, while biomass content and biogas composition are checked monthly. VFAs are checked using simple fluorescence-based test kits which simplify analysis and make it more affordable. The other wet analysis was carried out in accordance with the international standard methods in this case to APHA (2005) using Hach $^{\mathrm{R}}$ pre-prepared reagents.

\section{B. Maize feedstock}

Stoke Bardolph Energy Crop plant (Severn Trent Water) was commissioned in 2010. The data presented here was collected over a 3-year period, 2010-2013.

The AD reactor is 2-stage CSTR type reactor in two parallel streams designed by Schmack $^{R}$. The first stage includes two digesters of $550 \mathrm{~m}^{3}$, each baffled into 2 sub chambers. Two secondary digesters are $3300 \mathrm{~m}^{3}$ in a single chamber. Gas is collected in a tertiary digester.

The plant can treat $37000 \mathrm{t}$ stock/year, where $34500 \mathrm{t}$ is maize, and $2500 \mathrm{t}$ wheat. Maize is grown on 1500 hectares of metals contaminated sacrificial land (from sewage sludge applications) and the whole plant is used for AD. The feed is chopped to between 6-9 mm and is between 28-34\% dry solids content depending on the state at harvest. It is ensilaged for 12 months and weight is exerted onto the surface of the clamp to squeeze out the air and create anoxic conditions and so to generate the acid rather than carbon dioxide. Ensillageing is the first step of the treatment process-hydrolysis. The total feed is 150 t/day, in small portions regularly fed throughout the day.

Feedstock additions are controlled via a loading cell and auger with a volume of $80 \mathrm{~m}^{3}$. The primary digester is maintained at $10.5 \%$ dry solids using recycled digestate, while the secondary digesters are at $9.5 \%$ dry solids by solids conversion. The total retention time of the process is 90 days: 40 days in each primary and secondary digesters at $42^{\circ} \mathrm{C}$ and 10 days in tertiary digester which is not heated.

Monitoring and analysis of substrates includes analysis of dry matter, volatile solids, $\mathrm{pH}$, acid levels, ammonium $-\mathrm{NH}_{4}-$ $\mathrm{N}$, and with a full nutrient sweep performed quarterly. Gas production is monitored continuously.

Gas produced through the AD process is used in a CHP plant. The heat is mostly used for the main sewage treatment works but part of it is used for heating the maize digesters. The power generated on site is $21 \mathrm{GWh}$ /year and it is being equally split between the mainly aerobic sewage treatment works and injection to the public electricity grid.

\section{RESULTS AND DISCUSSION}

The 2-year period of the Uniliver data can be divided in two distinct sections, before and after the scheduled maintenance works. Period before the maintenance is characterized by a good initial performance followed by the period of increasing instability towards the end of the first year. This was due to issue with reduction in sludge blanket height and solids losses. 
This period was characterized by the great variability of Ripley's ratio and increase in VFAs, both of which are indicators of overall reactor stability. Ripley's ratio for a healthy industrial $\mathrm{AD}$ reactor it is expected to have values below 0.5 . During the first year of operation, for the period of Jan-Dec 2011, Ripley's ratio of the reactor effluent had an average value of 0.4 , exhibiting great variability of the values (min=0.20, $\max =1.04$ ). In the early 2012 reactor has exhibited further instability in terms of Ripley's ratio. On the day preceding the shutdown and cleaning of the reactors, the highest measured value was 1.87. This was also accompanied with the lower biogas production. Following the shut-down period (Jan-March 2012), Ripley's ratio has exhibited significant improvement with an average value of 0.29 , indicating that the greater stability of the reactor has been reached. Following improvement in Ripley's ratio, biogas production increased approximately $40 \%$ in relation to the preshut-down production (Figure 1 bottom).

Stability of the reactor could further be analyzed using volatile fatty acid (VFA) values. For the initial period of JanDec 2011 VFA values had greater variability ranging from 52 to $2488 \mathrm{ppm}$. Peaks in VFA'a values correspond to increased values of Ripley's ratio. During the period before the shutdown VFA remained high and have reached concentrations of over $1000 \mathrm{ppm}$ in several instances. Increase in VFAs makes reactor content too acidic, which directly inhibits growth of methanogenic bacteria, hence suppressing biogas production. This is further followed by $\mathrm{pH}$ of the reactor dropping below 7 on several occasions. However, it should be noted that overall, $\mathrm{pH}$ values do not show clear difference between the two measuring periods (before and after shut-down). This is caused by the relative insensitivity of $\mathrm{pH}$ measurement because they are based on logarithmic scale. On the other hand, VFA measurement represent very good indicator of the reactor's performance. It should be noted here that VFAs in the described AD facilities was determined using simple fluorescence-based test kits. This kit provides accurate and rapid in situ analysis of VFA in samples, simplifying analysis and making it more affordable.

In the observed period of two years, TCOD of the buffered waste water varies from $5500 \mathrm{mg} / \mathrm{l}$ to $41400 \mathrm{mg} / \mathrm{l}$, which is in the range of previously reported values (Parawira 2005, Baloch 2007). For the waste water flow, this results in the average total COD load of $4800 \mathrm{~kg} /$ day for the first year of operation, and $5800 \mathrm{~kg} /$ day for the second year, as shown in Figure 1top. Based on the average flow for the two years of operation, an average organic loading rate (OLR) for the two years of operation is $18 \mathrm{~kg} \mathrm{COD} / \mathrm{m}^{3} /$ day and $26 \mathrm{~kg} \mathrm{COD} / \mathrm{m}^{3} / \mathrm{day}$, respectively. This is in accordance with the values previously reported in literature (Franklin, 2001, Baloch 2007). Due to the variable flow rates, hydraulic retention time (HRT) in present study varied over the course of 2 years, but on the average HRT was 4.4 days. It is noteworthy that the COD of the buffered waste water is mostly in the form of soluble COD (SCOD), as sugar and alcohols. For the reporting period of two years the average percentage of SCOD in COD was $84.5 \% \pm 10.6 \%$. SCOD is readily converted to biogas and this saves costs on the avoiding complex pre-hydrolysis treatments. The removal efficiency will further be boosted by HRT which is somewhat high for such a highly biodegradable substrate.
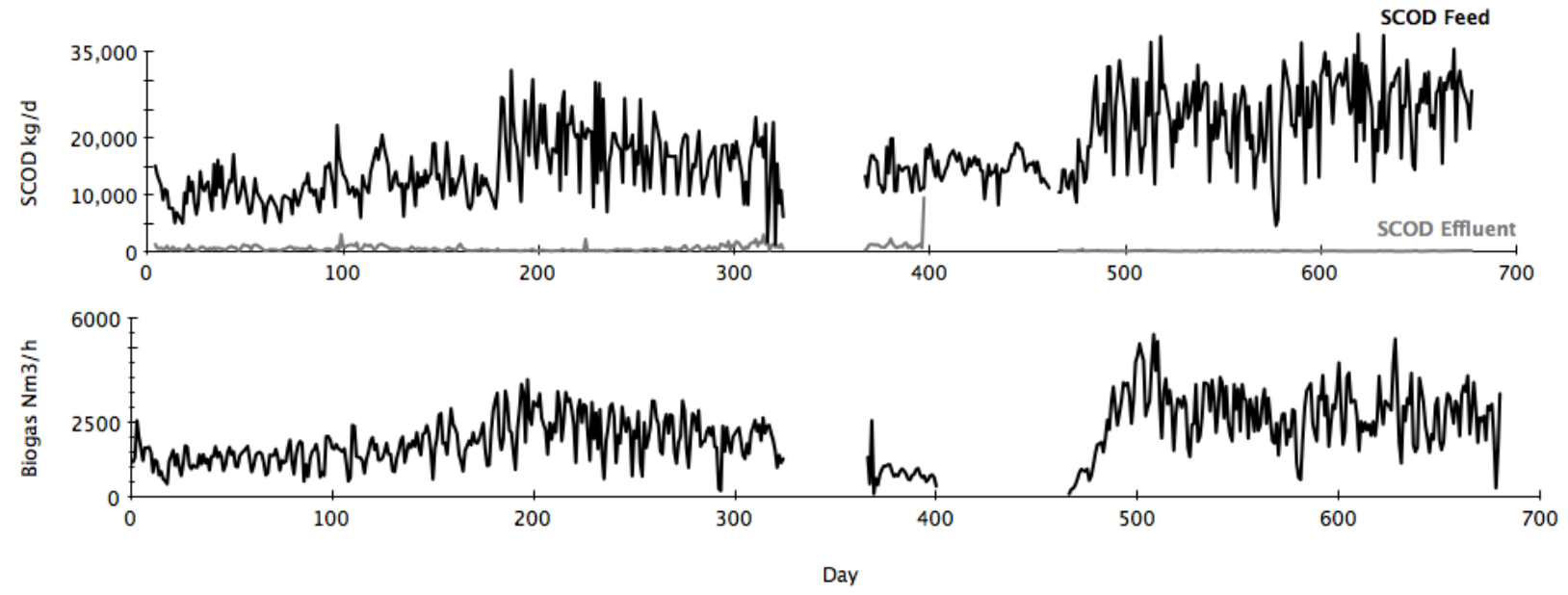

Figure 1.Brewery waste treatment. Top: SCOD removal; bottom: biogas production

The gas production was directly correlated to the SCOD removal and on average it was of $0.4 \mathrm{l} \mathrm{CH}_{4} / \mathrm{g}$ COD removed. The percentage of methane in produced biogas was $70 \pm 9 \%$ in the second year of operation. His is somewhat higher than the values reported by Bocher et al (2008) of 62\% methane, and similar to Baloch et al (2007) with $62 \%$ to $75 \%$ methane.

Severn Trent Water data for maize digestion show great stability of the process. Gas production over the reported period of 3 years shows an average gas production of 21205 $\mathrm{m}^{3}$ /day. Considering the daily feed of $150 \mathrm{t} /$ day, there are 141 $\mathrm{m}^{3}$ of gas being produced per ton of feed. In relation to the working volume of the digester (including primary and secondary digesters), there is $2.75 \mathrm{~m}^{3}$ of gas being produced per $\mathrm{m}^{3}$ of active reactor volume. The gas quality analysis indicates $50-60 \%$ of methane in biogas, which is in accordance with published literature (Heiermann 2009). 
Volatile solids in reactor decrease from the initial 28-34\% solids in the ensilaged maize to $8-9 \%$ in the post-digester. This indicates $72 \%$ removal rate for volatile solids.

The stability parameters further confirm steady performance of the digester. The $\mathrm{pH}$ is remaining close to 7.0 for the entire duration of the monitoring period. Similarly, ammonium and fatty acids are within the normal range and show the optimal metabolic processes in the digester. For example, ammonium remains close to $3.2 \mathrm{~kg} / \mathrm{t}$ throughout. Digester health is further maintained by regular addition of urea, iron, cobalt, molybdenum, and selenium.
It can be noticed that, when compared to the brewery waste data, maize digestion exhibits greater stability. This is mainly due to the steady, regular feeding regime of the maize processing facilities with no shocks to the digester with small feedings being introduced throughout the day. In contrast, brewery waste facilities' flow rate and COD of the waste vary significantly throughout the monitoring period. Due to the difference in the feedstock, maize $\mathrm{AD}$ requires significantly longer retention time to breakdown cellulose and lignin in maize.

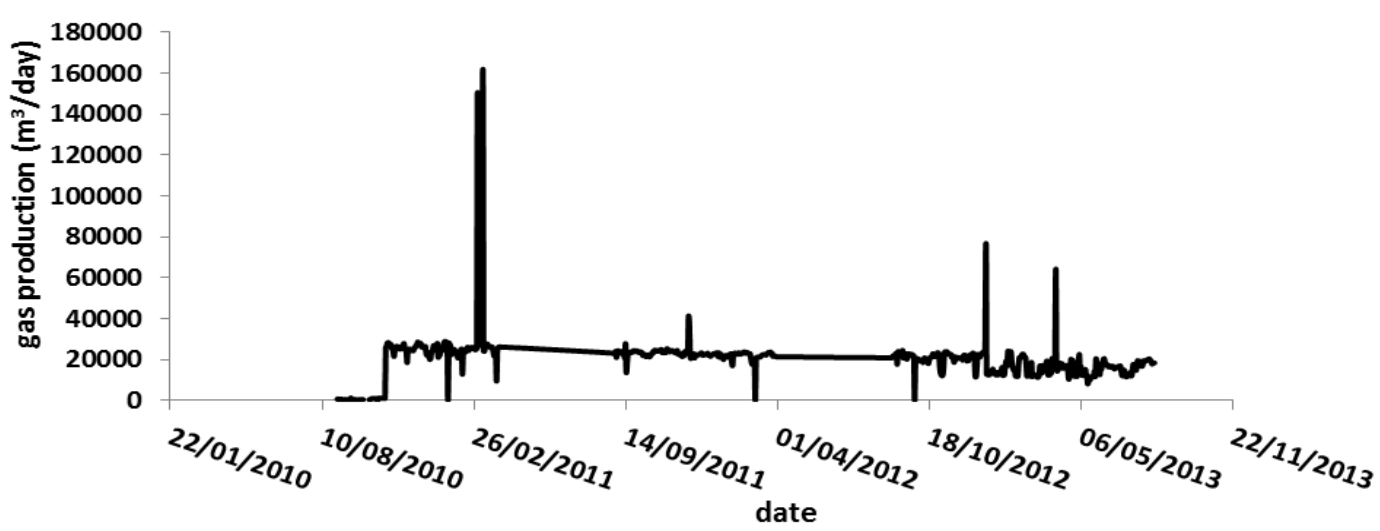

Figure 2. Anaerobic digestion of maize (Sevren Trent Waters): gas production

The stable process in maize digestion provides steady flow of biogas with relatively small variability in production. This provides reliable source of energy. In contrast with maize facilities, brewery waste processing gives high variance in biogas flow as a result of variability in the feedstock throughout the process. This also confirms the need for buffering in case of brewery waste, as the range in flow rate was $12-774 \mathrm{~m}^{3} /$ day (with an average of $246 \mathrm{~m}^{3} /$ day), COD in the raw effluent from $5500 \mathrm{mg} / \mathrm{l}$ to $41400 \mathrm{mg} / \mathrm{l}$. These ranges were typical of previous work on brewery effluents.

The above data suggests that simple VFA analysis kits provide reliable information on digester health. The VFA is shown to be more reliable parameter when compared to simple biogas production monitoring or $\mathrm{pH}$ of the digestate, both of which show less sensitivity.

The initial problems in EGSB performance were caused by overloading of biomass. This was followed by the scheduled plant refurbishment works. Once opened and inspected, it was noted that the ceramic lining within the stainless steel EGSB tank was corroded and damaged, and the formation of buildup within the EGSB reactor was noted. The deposit on the walls of the reactors is believed to be struvite. This has resulted in poorer mixing and flow within the tank, and it has affected the overall performance. This is a great example of sensitivity of the $\mathrm{AD}$ process, where overloading of the reactor and concentration shocks have caused damage and overall process instability.

\section{ACKNOWLEDGMENT}

Authors would like to thank Severn Trent Water Stoke Bardolph Energy Crop Plant and Marmite Uniliver Burton upon Trent plant for their collaboration on this work.

This work is in part funded by the Engineering and Physical Sciences Research Council (EPSRC) UK.

\section{REFERENCES}

http://www.biogas-info.co.uk/index.php/incentives-qa.html. Accessed 15/10/2013

K. Leal, E. Chacin, E. Behling, E. Gutierez, N. Fernandeza, and C.F. Forstef, "A mesophilic digestion of brewery wastewater in an unheated anaerobic filter," Bioresource Technology, 1998, 65, 5 l-55.

W. Parawira, I. Kudita, M.G. Nyandoroh, and R. Zvauya, “A study of industrial anaerobic treatment of opaque beer brewery wastewater in a tropical climate using a full-scale UASB reactor seeded with activated sludge,” Process Biochemistry, 2005, 40, 593-599.

M.I. Baloch, J.C. Akunna, and P.J. Collier, “The performance of a phase separated granular bed bioreactor treating brewery wastewater,” Bioresource Technology, 2007, 98, 1849-1855. M.X., Zheng, K.J. Wang, J.E. Zuo, Z. Yan, H. Fang, and V. $\mathrm{Yu}$, "Flow pattern analysis of a full-scale expanded granular sludge bed-type reactor under different organic loading rates," Bioresource Technology, 2012, 107, 33-40 
R. J. Franklin, "Full-scale experiences with anaerobic treatment of industrial wastewater," Water Science and Technology, 2001, 44(8), 1-6.

Y. Ahn, K. Min, and R.E. Speece, "Pre-acidification in anaerobic sludge bed process treating brewery waste water,“ Water Research, 2001, 35 (18), 4267-4276.

S. Connaughton, G. Collins, and V. O’Flaherty, "Psychrophilic and mesophilic anaerobic digestion of brewery effluent: A comparative study,” Water Research, 2006, 40, 2503 - 2510

R. Chandra, H. Takeuchi, and T. Hasegawa, "Methane production from lignocellulosic agricultural crop wastes: A review in context to second generation of biofuel production," Renewable and Sustainable Energy Reviews, 2012, 16, 14621476
M. Heiermann, M. Plochl, B. Linke, H. Schelle, and C. Herrmann, "Biogas crops- Part I: Specifications and sustainability of field crops for anaerobic digestion," Agricultural Engineering International: the CIGE Ejournal, 2009, 1087, XI

APHA Standard Methods for the Examination of Water and Wastewater 1995 22 ${ }^{\text {nd }}$ Edition American Public Health Association Washington, USA.

B.T. Bocher, M.T. Agler, M.L. Garcia, A.R. Beers, and L.T. Angenent, “Anaerobic digestion of secondary residuals from an anaerobic bioreactor at a brewery to enhance bioenergy generation," Journal of Industrial Microbiology and Technology, 2008, 35, 321-329 